\title{
A REVOLUÇÃO DAS TECNOLOGIAS DE INFORMAÇÃO E COMUNICAÇÃO: CONSEQÜÊNCIAS SOCIAIS, ECONÔMICAS E CULTURAIS
}

\section{Lívia Bergo Coelho Ferreira}

\section{Resumo:}

O presente trabalho tem como objetivo analisar as conseqüências do surgimento e utilização das novas tecnologias de informação e comunicação (NTIC), nos dias de hoje e num futuro próximo. Questionamos quais seriam os efeitos mais profundos e alterações irreversíveis ocasionadas pela incorporação desse tipo de tecnologia. Para tanto, identificamos os processos dominantes em nossa atual realidade, cada vez mais baseados na lógica das redes, que se tornaram o modo principal de organização das atividades humanas. Também as influências sociais, econômicas e culturais são questões fundamentais a serem pautadas quando estudamos elementos com tamanha penetração e com estreita relação com as formas de poder. Por fim, discutimos o acesso às NTIC, que, ao mesmo tempo que conectam indivíduos de todas as partes do mundo, fazem daqueles já excluídos do acesso às tecnologias pessoas ainda mais desconectadas. Um dos objetivos é entender como essa exclusão se dá, neste espaço cada vez menos físico.

\section{Palavras-chave:}

NTIC; redes; poder; acesso

\section{THE REVOLUTION OF INFORMATION AND COMMUNICATION TECHNOLOGIES: SOCIAL, ECONOMIC AND CULTURAL CONSEQUENCES}

\begin{abstract}
:
This study aims to analyze the consequences of the appearing and use of new information and communication technologies (ICTs), today and in the near future. It calls into question what are the more profound effects and irreversible changes caused by the incorporation of such technology. Thus, we have identified the dominant processes in our present reality, increasingly based on the logic of networks, which became the main organization form of the human activities. Also, social, economic and cultural influences are fundamental issues to be considered when studying elements with such penetration and that close to the forms of power. Finally, we discuss access to ICTs, which, while connecting people from all over the world, make those already excluded from access to technologies even more disconnected people. One of the goals here is to understand how this exclusion is done in this space each time less physical.
\end{abstract}

\section{Keywords:}

NICTs; Networks, Power, Access

(c) Revista Digital de Biblioteconomia e Ciência da Informação,Campinas, v.7, n. 1, p. 117-127, jul./dez. 2009- ISSN: 1678-765X. 


\section{Introdução}

Há muitos anos se discute as vantagens e desvantagens trazidas pelas novas tecnologias de informação e comunicação (NTIC), dentro da sociedade. Para muitos, tais instrumentos mudaram tanto a maneira de nos expressarmos quanto a maneira de pensarmos, alterando profundamente nossa cultura e tornando-se elementos fundamentais a serem pautados quando pensamos sobre o futuro da humanidade. Diante desse tipo de consideração - que muitas vezes foca-se na discussão a respeito da chamada mídia de massa $^{1}$-, mostra-se extremamente importante investigarmos as conseqüências da adoção indiscriminada das NTIC.

O argumento de que as novas tecnologias mudam a forma como nos comunicamos e, até, pensamos é bastante relevante. Durante toda a história da humanidade, novas descobertas e invenções forçaram nossos códigos de linguagem - especialmente as línguas - a evoluírem. E não é senão através desses códigos que nos expressamos e pensamos. Como prova disso, os jargões e termos específicos das comunicações tornaram-se parte de nosso vocabulário comum. É estranho, inclusive, percebermos que computadores, Internet, multimídia e realidade virtual são palavras que passaram a integrar nosso dia-a-dia há menos de 20 anos, tamanha sua penetração e utilização corrente nos dias de hoje.

Porém, quais seriam os efeitos mais profundos da incorporação desse tipo de tecnologia? Será que nossa percepção de tempo e espaço alterou-se irreversivelmente, como defendem alguns pesquisadores? E quais as conseqüências de tais mudanças para questões-base de nossa sociedade, tais como as regras ou normas sociais e morais dantes estabelecidas?

Para Beatriz Muniz Freire (2004, p. 1), é impossível desvincular o desenvolvimento das comunicações e formas de expressão humanas da formação cultural de uma sociedade. Isso porque

a rede de significados e práticas de um grupo social é o que chamamos de cultura. Quer dizer, tudo o que os homens e mulheres aprendem com o grupo em que vivem, a começar pela língua que falam, seu modo de definir o que é feio ou bonito, certo ou errado, as técnicas, as regras sociais, as formas de expressão,

\footnotetext{
${ }^{1}$ Do inglês mass media, refere-se aos veículos capazes de atingirem o maior número de pessoas possível, sem distinção de sexo, idade ou classe social. Opõe-se ao conceito de mídia segmentada.
}

(c) Revista Digital de Biblioteconomia e Ciência da Informação,Campinas, v.7, n. 1, p. 117-127, jul./dez. 2009- ISSN: 1678-765X. 
tudo isso é cultura. [...] cultura, no sentido antropológico, tem muito a ver com comunicação [...].

E é essa capacidade de ocasionar mudanças fundamentais em nossa cultura que vem sendo estudada por diferentes pesquisadores. Seu potencial revolucionário é reconhecido por entusiastas e alarmistas, sendo comparado com a invenção da imprensa ou a Revolução Industrial (CASTELLS, 1999). Estamos diante do surgimento iminente da convergência absoluta de todas as mídias: uma máquina multitarefa e (com o perdão da redundância) multimídia, com capacidade para acessar em tempo real toda e qualquer informação armazenada em toda e qualquer parte do mundo. E tal acesso, claro, se daria de acordo com a conveniência do usuário.

O processo para que tal previsão se torne realidade corre a passos largos. Como bem identificam Kalman e Rafaeli (2007),

Nos últimos anos, temos visto a confluência de quatro tendências que estão desfazendo lentamente a dicotomia entre mídias síncronas e assíncronas, sendo elas digitalização, convergência de mídias, conectividade ininterrupta e portabilidade. Devido à facilidade e ubiqüidade das tecnologias de digitalização (Negroponte, 1996), mais e mais comunicação é digitalizada, e isso inclui não só palavras escritas, mas também imagens, vídeos, voz e música. A convergência de mídias (Koskinen, 2000) alavanca a digitalização e esfacela as fronteiras entre meio e mensagem (p. 2, grifo do autor, tradução nossa).

A convergência significará uma quebra de paradigmas, ao deixar para trás antigos parâmetros comunicacionais. Não faria mais sentido, por exemplo, mantermos a classificação dos níveis de interatividade propostos por Reisman ${ }^{2}$ ou a divisão entre mídias quentes e frias adotada por McLuhan ${ }^{3}$. Tais discussões tornariam-se completamente ultrapassadas.

É diante dessa nova organização, regente de tais mudanças, que deve emergir uma nova forma de pensarmos e nos expressarmos, a qual não se limitaria às dimensões impostas pelo tempo e espaço. Estaríamos, enfim, envoltos por uma multiplicidade de dimensões,

\footnotetext{
${ }^{2}$ São três: reativo (as opções e realimentações são dirigidas pelo programa, havendo pouco controle do usuário sobre a estrutura do conteúdo); coativo (há possibilidades de o usuário controlar a seqüência, o ritmo e o estilo); pró-ativo (o usuário pode controlar tanto a estrutura quanto o conteúdo) (REISMAN, 2002).

${ }^{3}$ Para McLuhan (1964), as mídias quentes são aquelas que não deixam nenhum (ou muito pouco) espaço de interação. Distribuem mensagens prontas, sem possibilidade de intervenção. Já as mídias frias permitem a interatividade e deixam um lugar livre, que os usuários podem preencher ao interagir.
} 
ainda que virtuais, que fariam das estruturas comunicacionais algo completamente diferente do que conhecemos hoje.

Esse futuro por muitos vislumbrado é alvo de diferentes tipos de questionamentos. Há quem acredite que ele trará uma nova era, pautada pela liberdade individual, e que as NTIC permitirão que processos fundamentais de nossa sociedade - como a comunicação, educação e geração de capital, por exemplo - se dêem de forma segmentada, orientada para os indivíduos, em oposição àquela disseminada pelas mídias de massa.

Os menos otimistas, porém, chamam atenção para uma outra realidade possível, dominada por uma nova elite e povoada por um novo tipo de classe excluída: os carentes de tecnologia e informação. Sem a democratização do acesso a tais "bens”, de nada adiantaria a promessa libertadora da segmentação.

Em outras palavras, as grandes transformações não dependem apenas da evolução dos aparatos tecnológicos envolvidos, mas também - e para alguns principalmente - da maneira como eles são utilizados e organizados. E, como veremos, sua adoção não está desvinculada dos princípios ideológicos que sempre regeram a existência da humanidade.

\title{
Uma tecnologia em rede
}

É fácil identificarmos, hoje, o quanto as NTIC tornam-se ferramentas indispensáveis - e por que não dizer intrínsecas - à geração de riqueza, ao exercício do poder ${ }^{4}$ e à criação de códigos culturais. Porém, tais inovações potencializaram uma forma de organização social já antiga: as redes.

Como identificou Castells (1999, p. 78)

\begin{abstract}
essa configuração topológica, a rede, agora pode ser implementada materialmente em todos os tipos de processos e organizações graças a recentes tecnologias da informação. Sem elas, tal implementação seria bastante complicada. E essa lógica de redes, contudo, é necessária para estruturar o não-estruturado, porém preservando a flexibilidade, pois o não-estruturado é a força motriz da inovação na atividade humana.
\end{abstract}

\footnotetext{
4 “Poder é aquela relação entre os sujeitos humanos que, com base na produção e na experiência, impõe a vontade de alguns sobre os outros pelo emprego potencial ou real de violência física ou simbólica” (CASTELLS, 1999, p. 33).
}

(c) Revista Digital de Biblioteconomia e Ciência da Informação,Campinas, v.7, n. 1, p. 117-127, jul./dez. 2009- ISSN: 1678-765X. 
Tal estrutura é formada por um conjunto de nós, interconectados por ligações, mais comumente chamadas de links. As redes, como estruturas abertas capazes de expandiremse de forma ilimitada, estão sempre aptas a abranger novos nós, desde que estes consigam comunicar-se dentro delas, ou seja, compartilhem os mesmos códigos de comunicação. E, entre esses nós, destacam-se os conectores. Como define Barabási (2003, p. 56),

Conectores - nós com um número anormal de ligações, estão presentes em variados sistemas complexos, desde a economia até as células. Eles são uma propriedade fundamental da maioria das redes, um fato que intriga cientistas de disciplinas díspares, como biologia, ciência da computação, e ecologia (tradução nossa).

Os processos dominantes em nossa atual realidade estão cada vez mais baseados em redes. Elas tornaram-se o modo principal de organização das atividades humanas, transformando, a partir de sua lógica, todos os domínios da vida socioeconômica. A Sociedade em Rede, definida por Castells (1999), é caracterizada por uma nova morfologia social, um sistema aberto dinâmico capaz de abarcar inovações sem comprometer seu equilíbrio.

A difusão da lógica das redes modifica a operação e os resultados dos processos produtivos e de experiência, poder e cultura. A presença da rede ou a ausência dela e as relações entre as redes entre si são fonte de dominação e transformação na sociedade. E os conectores são os detentores do poder, ou seja, as conexões que ligam as redes são os instrumentos do poder.

Nesse contexto, o capitalismo se reestruturou e, hoje, dá forma às relações sociais em todo o planeta.

Redes são instrumentos apropriados para: a economia capitalista baseada na inovação, globalização e concentração descentralizada; para o trabalho, trabalhadores e empresas voltadas para a flexibilidade e adaptabilidade; para uma cultura de desconstrução e reconstrução contínuas (CASTELLS, 1999, p. 498).

Nesse sentido, as relações sociais entre capital e trabalho sofreram profunda transformação. O informacionalismo ${ }^{5}$ leva à concentração e globalização do capital

\footnotetext{
${ }^{5}$ Ao contrário do industrialismo - voltado para o crescimento da economia, maximização da produção - o informacionalismo visa o desenvolvimento tecnológico, a acumulação de conhecimento e elevação dos níveis de complexidade do processamento de informação.
}

(c) Revista Digital de Biblioteconomia e Ciência da Informação,Campinas, v.7, n. 1, p. 117-127, jul./dez. 2009- ISSN: 1678-765X. 
exatamente pelo emprego do poder descentralizador das redes, incorporados em sua estrutura e linguagem.

Sob essas condições, a Internet tornou-se uma alavanca na transição para a nova sociedade em rede. Para Castells (2003, p. 46), ela é, sem dúvida, uma tecnologia da liberdade, que possibilita agirmos sobre nós mesmos - tanto individual quanto coletivamente -, usarmos a tecnologia a nosso favor e interferir na qualidade de vida da sociedade.

As fontes culturais da Internet não podem ser reduzidas, porém, aos valores dos inovadores tecnológicos. Os primeiros usuários de redes de computadores criaram comunidades virtuais [...], desenvolveram e difundiram formas e usos na rede: envio de mensagens, lista de correspondência, salas de Chat, jogos para múltiplos usuários, conferências e sistema de conferência. [...] essas comunidades trabalham com base em duas características fundamentais. A primeira é de valor da comunicação livre, horizontal [...] o segundo valor compartilhado que surge das comunidades virtuais é o que eu chamaria formação autônoma de redes.

As NTIC e o poder de incluir e excluir

Nessa nova era, completamente permeada e dominada pela demanda e, por que não dizer, necessidade de informação, a habilidade de comunicar torna-se cada vez mais um poder de comunicar. Um ponto de discordância entre diversos autores é a definição exata das alterações a serem promovidas num futuro próximo e a previsão sobre quem terá acesso a tal poder.

Os veículos de comunicação, tradicionalmente, têm uma relação direta com essa questão. A mídia é sempre reconhecida como instrumento de poder e propagadora de ideologias. O monopólio de grandes redes de comunicação, em todo o mundo, só corrobora essa constatação.

Nos últimos anos, porém, tal status quo tem sido incomodado pelo crescimento do acesso às NTIC. O ambiente virtual criou novos espaços de comunicação e, mais do que isso, proporciona ao usuário a possibilidade de geração de conteúdo. Algo sequer cogitado há até poucos anos. E “a rede continua a evoluir, de um mundo regulado pela mídia de 
massa e audiência também de massa para outro regulado por uma mídia confusa e participação também confusa” (KELLY, 2005, p. 1, tradução nossa).

Entretanto, mesmo migrando para o novo espaço virtual, os veículos de comunicação não alteraram sua lógica capitalista, ou seja, não se tornaram provedores de conteúdo livres de interesses comerciais. Dessa forma, o que esperar das comunicações no ambiente digital?

Enquanto alguns autores consideram que as NTIC - com sua forma de organização horizontal - trazem consigo uma possibilidade de libertação em relação à manipulação praticada através das mídias anteriores, outros temem que esse potencial não seja suficiente para sobrepor o processo de fragmentação social em curso. É o que identifica Castells (1999, p. 23):

Nesse mundo de mudanças confusas e incontroladas, as pessoas tendem a reagrupar-se em torno de identidades primárias: religiosas, étnicas, territoriais, nacionais. [...] Enquanto isso, as redes globais de intercâmbios instrumentais conectam e desconectam indivíduos, grupos, regiões e até países, de acordo com sua pertinência na realização dos objetivos processados na rede, em um fluxo contínuo de decisões estratégicas.

Ou seja, esse tipo de poderio conferido às NTIC nos conduziriam a uma forma diferenciada de relações: as políticas da informação. Segundo Silveira \& Santana, “as tecnologias da informação são ambíguas. Servem ao controle e à liberdade, ao aberto e ao орасо”.

Entretanto, dizer ao certo quem irá controlá-las é algo ainda arriscado. Mas as disputas entre grupos antagônicos já levantam questões amplamente discutidas, como a cidadania na rede.

\begin{abstract}
De um lado, as operadoras de telecom querendo controlar a voz sobre IP, de outro o movimento Save the Internet ${ }^{6}$, articulando a defesa da neutralidade dos protocolos da rede. As indústrias do entretenimento querendo impor o $\mathrm{DRM}^{7}$ e organizações como a Eletronic Frontier Foundation lutando pela liberdade de expressão e pelos inalienáveis direitos humanos na rede. Defender a diversidade cultural na rede passa pela defesa de uma cidadania digital, transnacional, e baseada na garantia dos direitos humanos e das liberdades fundamentais. (CASTELLS, 999, p. 23).
\end{abstract}

\footnotetext{
${ }^{6}$ Sob o slogan "Fighting for Internet Freedom", o movimento contesta a ação de empresas de telecomunicações e corporações da indústria do entretenimento que vêm tentando controlar transmissões de dados na rede mundial de computadores. Tais companhias têm buscado apoio no Congresso norteamericano por se sentirem ameaçadas pelo avanço de tecnologias como a VoIP, o rádio pela web e a webTV. O site do movimento é http://www.savetheinternet.com/.

7 Do inglês Digital Restrictions Management, é toda técnica que busca limitar artificialmente as capacidades de um dispositivo digital, de modo a privilegiar quem impõe a técnica e não o usuário do dispositivo.
}

(c) Revista Digital de Biblioteconomia e Ciência da Informação,Campinas, v.7, n. 1, p. 117-127, jul./dez. 2009- ISSN: 1678-765X. 
Mas a exclusão social é um processo já em estágio avançado. "O desafio é também entender como ela se dá - que sempre se deu - nesse espaço cada vez menos físico, cada vez menos geográfico da universalidade da máquina, da globalidade da vida, tecida na teia intrincada do fluxo e da circulação da informação” (VOGT, 2001, p. 1).

Estamos diante, afinal, de mais uma contradição trazida pelo processo de reestruturação das relações dentro da sociedade. O avanço tecnológico que hoje presenciamos, e do qual não podemos mais nos esquivar, promove a conexão irrestrita, consolidando a rede globalizada que vinha sendo estruturada nas últimas décadas. Porém, ao mesmo tempo que conecta indivíduos de todas as partes do mundo, faz daqueles já excluídos do acesso às tecnologias pessoas ainda mais desconectadas, cada vez mais distantes dessas instâncias de saber e poder.

\section{Conclusão}

Como foi explicitado anteriormente, as NTIC, desenvolvidas no ambiente em rede em que vivemos atualmente, alteraram profundamente configurações sociais e culturais de nossa sociedade, sem, porém, extinguir a forma de organização econômica dominante: o capitalismo. Este, pelo contrário, se reestruturou e adequou-se a tais avanços. Dessa maneira, as empresas do setor de comunicação absorveram diversas mudanças demandadas pela própria sociedade, sem, contudo, alterarem seu principal objetivo: o lucro. Esse panorama é extremamente desanimador para os que esperam ver realizado todo o potencial libertador e democratizante das NTIC. O capital ainda determina as escolhas tecnológicas e de conteúdo.

Um segundo ponto a ser considerado é que, ainda que estejamos imersos na "era digital” e prontos para todo um mundo de virtualidade, para fazer parte da “classe conectada” é preciso ter acesso ao aparato tecnológico demandado. E o preço disso ainda está longe de ser acessível à maioria da população mundial.

O enorme fluxo de informações e a rapidez com que elas circulam torna cada vez mais difícil a escolha consciente entre uma e outra. Há, além disso, uma busca incessante por essa rapidez de acesso, mas o tempo nunca será suficiente para usufruirmos de todas as informações desejadas ou disponíveis.

(c) Revista Digital de Biblioteconomia e Ciência da Informação,Campinas, v.7, n. 1, p. 117-127, jul./dez. 2009- ISSN: 1678-765X. 
De qualquer forma, apesar do pragmatismo de alguns autores, que dão tais mudanças como certas, os limites descritos não estão tão próximos de serem atingidos. Mas, ainda que o custo da maioria dos equipamentos de ponta seja elevado, se o potencial libertador e democratizante previsto por certos pesquisadores se realizar, talvez o grande investimento valha a pena.

Estamos, assim, diante de uma realidade dominada pelos conceitos do pós-modernismo e do capitalismo pós-fordista, em que o mercado virtual consegue atingir tanto o grande público (massa) quanto segmentos menores. E é difícil determinar em que medida as NTIC são agentes fundamentais dessas transformações ou apenas ferramentas que auxiliaram nesse processo.

Várias características de nossa realidade multimídia são capazes de revolucionar nossa maneira de comunicar. Mas a propulsão para que tal potencial seja utilizado é dada por ideologias (políticas, econômicas etc.) já difundidas no dito mundo "real”. O que significa dizer que, a nossa realidade virtual é criada por um imaginário apoiado numa outra bastante real.

E é aí que repousa a principal questão a respeito da revolução descrita por alguns pesquisadores: numa virtualidade com raízes tão claras em princípios do mundo real, corremos o risco de apenas transferir para um novo ambiente toda essa estrutura já consolidada. E dessa forma, estaríamos diante muito mais de um desenvolvimento natural - mais um passo da humanidade em direção aos avanços tecnológicos - do que de uma revolução em si.

Entretanto, apenas o fato de estarmos atentos a tais questões já nos credencia a alterarmos o curso dessas transformações, em busca de uma verdadeira revolução libertadora e superação de limites físicos. 


\section{Referências}

BARABÁSI, A. Linked. New York: Plume, 2003.

CASTELLS, M. A Sociedade em rede. São Paulo: Paz e Terra, 1999.

A galáxia da internet. Rio de Janeiro: Jorge Zahar, 2003.

FREIRE, B. M. O que é, o que é: Folclore e Cultura Popular. Boletim Salto para o Futuro - Cultura Popular e Educação, Rio de Janeiro: TV Escola, fev. 2003. Disponível em: <http://www.redebrasil.tv.br/salto/boletins2003/cpe/teimp.htm>. Acesso em: 15 ago. 2007.

KALMAN, Y. M.; RAFAELI, S. Modulating synchronicity in computer mediated communication. Disponível em: http://www.kalmans.com/synchasynchICAsubmit.pdf>. Acesso em: 05 ago. 2007.

KELLY, K. We are the web. 2005. Disponível em: <http://www.kurzweilai.net/articles/art0629.html?m=1>. Acesso em: 29 ago. 2007.

MCLUHAN, H. M. Os meios de comunicação como extensões do homem. São Paulo. Cultrix, 1964.

REISMAN, R. R. Rethinking Interactive TV: I want my Coactive TV. Disponível em: <http://www.teleshuttle.com/cotv/CoTVIntroWtPaper.htm>. Acesso em: 05 agosto 2007.

SILVEIRA, S. A.; SANTANA, B. Diversidade digital e cultura. <http://diversidadedigital.blogspot.com/>. Acesso em: 25 ago. 2007.

VOGT, C. Informação e simulacro. Com ciência, n. 18, p. 1-3, mar. 2001. 


\section{Lívia Bergo Coelho Ferreira}

Possui graduação em Comunicação Social pela Universidade Federal de Minas Gerais (2006). Atualmente, é mestranda na linha de Tecnologias da Comunicação no mestrado em Comunicação da Universidade Federal de Juiz de Fora. liviabergo@gmail.com

Recebido em: 04/04/2008

Aceito para publicação em: jan/2009 